\section{Acolhimento no cuidado à saúde da mulher no puerpério}

\author{
Postpartum follow-up of women's health
}

\author{
Atención en el cuidado a la salud de la mujer \\ durante el puerperio
}

Maria Suely Medeiros Corrêa 1

Katia Virginia de Oliveira Feliciano 2

Evelyne Nascimento Pedrosa 2

Ariani Impieri de Souza 2,3

doi: 10.1590/0102-311X00136215

\section{Resumo}

Este artigo objetivou compreender percepções e práticas relativas ao acolhimento no cuidado puerperal à mulher. Ele é parte de pesquisa qualitativa mais ampla, fundamentada em Gadamer, efetuada de outubro de 2012 a setembro de 2013, em Recife, Pernambuco, Brasil, com observação participante e entrevista semiestruturada. Participaram equipe de saúde da família (médica, enfermeira e cinco agentes de saúde) e dez mulheres (18 anos e mais, último trimestre da gestação, pré-natal com a equipe). As categorias empíricas foram: acesso ao cuidado e demandas e necessidades de saúde. Os resultados destacam insatisfação com a visita domiciliar: tardia, sem priorização, médica/enfermeira ausente, assistemática e descontinuada; falta de consulta puerperal e acesso difícil ao médico. Há desagrado com a desvalorização das necessidades de saúde femininas: atenção focada no bebê, escassez de exame físico e anamnese, orientações insuficientes e comunicação limitada. A incipiência do acolhimento mostra a necessidade de transformar as práticas da equipe para conferir visibilidade à mulher, qualificando o cuidado puerperal.

Acolhimento; Período Pós-Parto; Atenção Primária à Saúde; Assistência à Saúde; Saúde da Mulher

\author{
Correspondência \\ A. I. Souza \\ Instituto de Medicina Integral Prof. Fernando Figueira. \\ Rua dos Coelhos 300, Recife, PE 51030-450, Brasil. \\ ariani@imip.org.br \\ 1 Universidade de Pernambuco, Recife, Brasil. \\ 2 Instituto de Medicina Integral Prof. Fernando Figueira, \\ Recife, Brasil. \\ 3 Faculdade Pernambucana de Saúde, Recife, Brasil.
}




\section{Introdução}

A mulher vivencia profundas transformações no puerpério, expondo-se à maior frequência de agravos que são causas específicas de morbimortalidade materna. O Ministério da Saúde, valendo-se do Programa de Humanização do Pré-natal e Nascimento (PHPN), recolocou em pauta o acesso e a qualidade do cuidado no ciclo gravídico-puerperal 1. Como parte da integralidade no Sistema Único de Saúde (SUS), o puerpério é uma das áreas básicas de atuação da Estratégia Saúde da Família (ESF), modelo preferencial da atenção primária à saúde no Brasil 2.

A integralidade está relacionada à ideia de saúde como direito de cidadania, logo, à humanização das práticas em saúde, associando as exigências técnicas aos interesses e necessidades de indivíduos e coletividades. No âmbito setorial, a integralidade precisa ser construída em cada unidade de saúde e na rede integrada e regionalizada de atenção, com garantia dos fluxos de referência e contrarreferência 3 .

No encontro profissional de saúde/usuário, cada membro da equipe deve articular o conhecimento técnico-científico à atitude ética e solidária, adotando o acolhimento como diretriz transversal do cuidado 4 . O processo de acolhimento configura os contextos de intersubjetividade que possibilitam a construção do vínculo, da corresponsabilidade e da autonomia no cuidado à saúde 3,4,5.

$\mathrm{O}$ acolhimento remete à relação oferta-demanda 5,6,7,8, escuta dos relatos objetivos e subjetivos das vivências dos usuários 3,4,5; afetividade e visão mais apurada na busca constante de identificar e atender as necessidades de saúde 3,5,6,7,8 e comunicação dialógica 3,5,7,9. Portanto, indica o caráter interativo, crítico e reflexivo do agir profissional, que busca a superação de uma prática clínica reduzida a protocolos padronizados 10 .

Nas unidades de saúde da família (USF), em geral, o acolhimento limita-se a uma atividade de recepção e triagem da demanda espontânea $5,6,7$. Os obstáculos ao acesso e a impessoalidade no atendimento provocam insatisfação nos usuários 6,7,8. Uma metassíntese com estudos de diferentes países, inclusive do Brasil, demonstrou que na percepção da mulher as necessidades no puerpério, especialmente as emocionais e reprodutivas, eram desconsideradas 11.

A hermenêutica filosófica de Gadamer 12,13 traz sugestões valiosas à reflexão do acolhimento no cuidado puerperal. Dessa perspectiva, a boa prática em saúde não decorre apenas do saber-fazer instrumental, mas igualmente importante é o diálogo que possibilita aproximar-se à verdade prática de um dado encontro, alcançada quando nos entendemos sobre algo. A construção da "verdade" é uma experiência aberta à ressignificação, requerendo a mediação entre o conhecimento técnico-científico e o saber do ser humano sobre si próprio. Entender-se sobre algo não significa concordar com a visão do outro, mas colocar-se em contato com outro horizonte.

Como parte de pesquisa que buscou compreender a percepção e práticas de puérperas e equipe da ESF (EqSF) no cuidado puerperal à mulher, neste artigo apresentam-se a percepção e as práticas relativas ao acolhimento no cuidado puerperal à mulher, considerando a dimensão organizacional (atividades ofertadas, agendas e marcação de consultas) e profissional (encontro profissional/usuária) do cuidado ${ }^{14}$. Espera-se trazer subsídios para repensar as políticas públicas voltadas à saúde da mulher e fortalecer o respeito e a confiança essenciais à corresponsabilidade e autonomia dos envolvidos no cuidado puerperal.

\section{Método}

Estudo qualitativo desenvolvido em Recife, Pernambuco, Brasil, entre outubro de 2012 e setembro de 2013, com uma EqSF e mulheres da sua área de cobertura, utilizando perspectiva gadameriana. Realizaram-se observação participante (observação direta, interlocução sobre o observado e leitura de documentos oficiais) e entrevista semiestruturada (mulheres e profissionais). A seleção da equipe foi intencional, com o apoio do grupo técnico do Distrito Sanitário VI, sendo elegíveis aquelas da ESF que estavam completas, tinham nível médio de desempenho na assistência gravídico-puerperal 15, cujas unidades não estavam em reforma e a violência pública não restringia a mobilidade na área.

Sete integrantes da EqSF que prestavam cuidado puerperal participaram: médica, enfermeira e cinco agentes comunitárias de saúde (ACS). De novembro de 2012 a março de 2013, realizou-se amostragem por exaustão 15,16, elaborando listagem que identificou 18 mulheres elegíveis: idade aci- 
ma de 18 anos, último trimestre da gestação e acompanhamento pré-natal com a EqSF. Incluíram-se dez mulheres. Houve duas recusas e seis exclusões: uma por falta de condições cognitivas, quatro por mudança de área e uma que foi acompanhada, apenas, no serviço de referência para pré-natal de alto risco. Neste artigo, apresentam-se os resultados relativos à observação participante e entrevista com as mulheres.

A pesquisadora de campo (M.S.M.C.), enfermeira familiarizada com métodos qualitativos, não conhecia as participantes do estudo antes da entrada no campo. Na observação, ela assumiu o papel de participante como observador 15,17. Manteve envolvimento prolongado com o cotidiano da EqSF, focalizando as situações do cuidado puerperal: organização da demanda e atenção no domicílio e serviço. O roteiro contemplou: processo de trabalho (interação, comunicação e procedimentos técnicos) e contexto da EqSF (integração e comunicação). Efetuaram-se anotações detalhadas no diário de campo. Para finalizar a observação, considerou-se reincidência e complementaridade das informações 15,16,17.

As mulheres foram entrevistadas no domicílio no terceiro trimestre da gestação, puerpério tardio

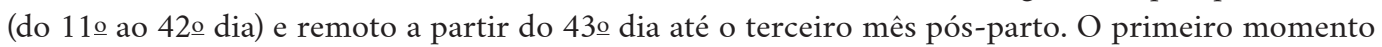
possibilitou à pesquisadora aproximar-se da mulher antes do parto, iniciando uma relação que potencializou a intersubjetividade nos encontros subsequentes. Os demais visaram a contemplar diferentes estágios do cuidado puerperal, sem sobrecarregar a mulher no puerpério imediato (até o 10o dia).

Em geral, efetuaram-se quatro sessões para explorar roteiro: gestação (desejo e planejamento, condições clínicas e afetivas da mulher, expectativas acerca do recém-nascido); puerpério (sentimentos, ideias, apoio informal, necessidades e demandas); e cuidado puerperal à mulher (acesso, interação, comunicação e ações desenvolvidas). Nas entrevistas, buscou-se garantir privacidade. O encerramento da coleta atendeu à constatação de saturação 16 . Cada mulher produziu, em média, 2 horas e 45 minutos de gravação, transcritas literalmente. Codificaram-se os excertos das mulheres como "M", seguidos do número atribuído a cada uma.

$\mathrm{Na}$ análise temática 16 , constituíram-se dois conjuntos com os materiais das entrevistas das mulheres e observação. Efetuou-se a leitura repetida de cada entrevista e nota de campo para identificar ideias, sentimentos e práticas relacionadas ao cuidado puerperal. As categorias empíricas desenvolvidas foram acolhimento e vínculo. Este artigo examina o acolhimento, contendo "acesso ao cuidado" e "demandas e necessidades de saúde". Quatro pesquisadoras realizaram a análise para ampliar a compreensão das inter-relações entre dimensão subjetiva e contextual 16, fundamentandose em Gadamer 13.

O projeto foi aprovado pelo Comitê de Ética em Pesquisa do Instituto de Medicina Integral Prof. Fernando Figueira (no 3012-12). As participantes assinaram Termo de Consentimento Livre e Esclarecido.

\section{Resultados e discussão}

A EqSF tinha 16 anos de atuação e sua área adscrita compreendia 935 famílias. As profissionais participantes eram mulheres, com idades entre 32 e 65 anos, e entre quatro e 16 anos de atuação na USF. As ACS completaram o Ensino Médio. Médica e enfermeira não tinham especialização em saúde da família. No âmbito do cuidado puerperal, os treinamentos realizados pela EqSF estavam dirigidos à promoção do aleitamento materno. O desligamento da médica na etapa final do trabalho de campo deu seguimento à rotatividade na EqSF, sobretudo de médicos e enfermeiros. A saída de profissionais da equipe representa um impasse na implementação da ESF, gerando fator de ruptura que prejudica a efetividade deste modelo assistencial 18 .

Cada membro da EqSF realiza aquilo que, na opinião dele, compete à sua área. A visita domiciliar puerperal é atribuição das ACS e enfermeira, a qual também responde pela escolha do contraceptivo na primeira consulta de puericultura. As mulheres são orientadas a efetuar revisão pós-parto na maternidade. A médica atende intercorrências e dá suporte à anticoncepção, quando outro membro da EqSF encaminha.

As mulheres entrevistadas tinham entre 19 e 27 anos de idade, metade cursara o Ensino Fundamental (completo ou incompleto), a maioria vivia em união consensual e sete eram primíparas. Todas 
realizaram o pré-natal com enfermeira e a maioria teve acompanhamento simultâneo da médica nas últimas semanas de gestação. Sete não receberam visita da ACS (horário de trabalho, mudança geográfica e redefinição da área). Cinco mulheres apresentaram hipertensão arterial na gestação e três tiveram parto normal (Tabela 1).

Duas mulheres planejaram a gravidez (suspenderam anticonceptivo), sendo indesejada para duas das oito que não planejaram a gestação. Quase todas apresentaram dificuldades no processo de amamentação e somente uma realizava aleitamento materno exclusivo quando da finalização da coleta. No cuidado à saúde da criança predominou a satisfação com o atendimento do filho na consulta de puericultura, e algumas mulheres reconheceram a contribuição das ACS.

\section{Acesso ao cuidado}

A operacionalização do acolhimento na ESF, frequentemente, restringia-se à organização da demanda espontânea 5,6,7,8. Embora divirjam dessa perspectiva, as correntes que afirmam a natureza dialógica do acolhimento admitem ser imprescindível garantir o acesso às atividades de saúde desenvolvidas 3,9. Reconhecendo o valor do diálogo entre aspectos objetivos e subjetivos do cuidado à saúde, Penchansky \& Thomas 19 definiram acesso como o grau de ajuste entre oferta e demanda, designando como acolhimento, ou adequação funcional, a dimensão do conceito que traduz a relação entre organização da oferta e percepção dos usuários da conveniência do arranjo proposto.

Segundo a normatização da Primeira Semana de Saúde Integral, os serviços de atenção primária à saúde devem realizar a visita domiciliar nos primeiros sete dias pós-alta da maternidade para avaliar as condições de saúde, orientar as ações promocionais e preventivas em saúde e identificar situações de riscos e intercorrências para a adoção de condutas adequadas. As ações no puerpério imediato envolvem, principalmente, o trabalho do enfermeiro articulado ao do ACS, sendo solicitada avaliação

Tabela 1

Características sociodemográficas e da atenção ao pré-natal e tipo de parto entre mulheres acompanhadas por equipe da Estratégia Saúde da Família (EqSF).

\begin{tabular}{|c|c|c|c|c|c|c|c|c|}
\hline \multirow[t]{2}{*}{ Código } & \multirow[t]{2}{*}{ Idade (anos) } & \multirow[t]{2}{*}{ Escolaridade } & \multirow{2}{*}{$\begin{array}{l}\text { Situação } \\
\text { conjugal }\end{array}$} & \multirow[t]{2}{*}{ Paridade } & \multicolumn{2}{|c|}{ Atenção pré-natal } & \multirow{2}{*}{$\begin{array}{l}\text { Intercorrência } \\
\text { na gestação }\end{array}$} & \multirow[t]{2}{*}{ Tipo de parto } \\
\hline & & & & & $\begin{array}{l}\text { Número de } \\
\text { consultas }\end{array}$ & $\begin{array}{c}\text { Visita } \\
\text { domiciliar }\end{array}$ & & \\
\hline M1 & 22 & $\begin{array}{c}\text { Superior } \\
\text { incompleto }\end{array}$ & Casada & 1 & 16 & $\operatorname{Sim}$ & $\begin{array}{l}\text { Hipertensão } \\
\text { arterial }\end{array}$ & Cirúrgico \\
\hline M2 & 27 & $\begin{array}{c}\text { Fundamental } \\
\text { completo }\end{array}$ & $\begin{array}{c}\text { União } \\
\text { consensual }\end{array}$ & 2 & 8 & Não & - & Normal \\
\hline M3 & 19 & $\begin{array}{l}\text { Fundamental } \\
\text { incompleto }\end{array}$ & $\begin{array}{c}\text { União } \\
\text { consensual }\end{array}$ & 1 & 8 & Sim & $\begin{array}{l}\text { Hipertensão } \\
\text { arterial }\end{array}$ & Cirúrgico \\
\hline M4 & 21 & $\begin{array}{c}\text { Fundamental } \\
\text { completo }\end{array}$ & $\begin{array}{c}\text { União } \\
\text { consensual }\end{array}$ & 1 & 8 & Não & $\begin{array}{l}\text { Hipertensão } \\
\text { arterial }\end{array}$ & Cirúrgico \\
\hline M5 & 20 & Médio completo & Casada & 1 & 9 & Sim & $\begin{array}{l}\text { Hipertensão } \\
\text { arterial }\end{array}$ & Cirúrgico \\
\hline M6 & 22 & Médio completo & $\begin{array}{c}\text { União } \\
\text { consensual }\end{array}$ & 4 & 5 & Não & Anemia & Cirúrgico \\
\hline M7 & 19 & Médio completo & Solteira & 1 & 10 & Não & $\begin{array}{l}\text { Infecção } \\
\text { urinária }\end{array}$ & Cirúrgico \\
\hline M8 & 18 & Médio incompleto & $\begin{array}{c}\text { União } \\
\text { consensual }\end{array}$ & 1 & 8 & Não & - & Normal \\
\hline M9 & 26 & $\begin{array}{l}\text { Fundamental } \\
\text { incompleto }\end{array}$ & $\begin{array}{c}\text { União } \\
\text { consensual }\end{array}$ & 1 & 6 & Não & $\begin{array}{l}\text { Hipertensão } \\
\text { arterial }\end{array}$ & Cirúrgico \\
\hline M10 & 22 & $\begin{array}{c}\text { Fundamental } \\
\text { completo }\end{array}$ & $\begin{array}{c}\text { União } \\
\text { consensual }\end{array}$ & 2 & 7 & Não & - & Normal \\
\hline
\end{tabular}


médica quando são detectadas alterações ${ }^{1}$. O Ministério da Saúde preconiza a programação rotineira das visita domiciliar pelas equipes para priorizar indivíduos e famílias de maior risco 2 .

Semelhante a outras pesquisas 11 , a atual indica a importância conferida pelas mulheres ao puerpério imediato e o descontentamento com a oferta da visita domiciliar. Relatos e observação mostram que a ACS visitou duas mulheres na primeira semana pós-alta e, na segunda quinzena, uma delas foi visitada pela enfermeira. Afora duas que não receberam visita domiciliar de nenhum membro da EqSF, as demais foram visitadas pela ACS no primeiro mês.

"Não recebi a visita não. Eu acho que não tiveram cuidado no pós-parto. (...) O cuidado maior e indispensável deveria ter sido no primeiro momento, que depois tudo é mais fácil” (M1).

O planejamento da visita domiciliar é inexistente, em conformidade com estudos na atenção primária à saúde 20,21. Não é priorizado o cuidado às primíparas, tampouco àquelas que apresentaram hipertensão gestacional, embora metade das mortes maternas no mundo tenha entre suas causas a hipertensão arterial 22. Como noutros contextos 11, as mulheres solicitam priorização das primíparas. A inexperiência e incertezas daquelas de primeiro filho tornam mais crítico o autocuidado e o desempenho do papel de mãe na transição da maternidade para casa. A vulnerabilidade sentida no pós-parto cirúrgico faz solicitar, igualmente, a precedência do cuidado nessa situação. Para elas, a ocorrência de uma dessas condições exige a visita dos profissionais na primeira semana.

As expectativas insatisfeitas acerca da visita domiciliar no puerpério imediato provocam nas mulheres um sentimento de desconsideração pelas necessidades delas e dos seus bebês. Usualmente referem incômodos nas mamas ("ferida", "endurecida", "doendo muito") e temor quanto à cicatrização dos pontos e "quebra" do resguardo, sendo comum apoiarem-se nas orientações dadas na maternidade e por familiares. A ausência da médica e enfermeira, sobretudo desta última, é questionada. Análogo aos estudos desenvolvidos em USF 23,24, neste, existe ampla compreensão da visita como facilitador do acesso ao cuidado numa situação de mobilidade restringida. A presença desses profissionais é supervalorizada porque pode propiciar atendimento resolutivo sem exigir deslocamento até o serviço. Comparável ao verificado por Bernardi et al. 25 , a mulher se sentiria segura e valorizada se recebesse essa visita.

"Foi muito bom quando [enfermeira] veio, porque eu não tinha marcado nenhuma consulta pra ela, não tava podendo ir" (M2).

A maioria das puérperas reclama do caráter assistemático ou da descontinuação do acompanhamento da ACS, e gostaria que as visitas domiciliares fossem mais frequentes. No Brasil, a Política Nacional de Atenção Básica (PNAB) estabelece que a ACS realize uma visita mensal a cada família da sua microárea de abrangência. Contudo, uma dada situação pode requerer intervalo menor entre as visitas 2 . Nesta pesquisa, consonante à realizada por Cunha \& Sá 21, as ACS definem a própria agenda sem objetivos pactuados em equipe.

"Queria que a visita dela [ACS] fosse mais constante na casa da pessoa, que ela viesse ver se tá precisando de alguma coisa... Não demorasse tanto a fazer as visitas" (M5).

Outros estudos têm observado insatisfação com a frequência da visita domiciliar e a dificuldade de inserção dos profissionais da ESF nestas visitas 20,21,23, que em geral eram centralizadas nos ACS e raramente realizadas pelo médico ${ }^{18,20}$. A superposição de atribuições e o elevado número de famílias adscritas limitavam participação dos membros da equipe nas visita domiciliar 20,21. Ademais, a abordagem do ACS por outros moradores no caminho, a necessidade de concentrar as visitas numa mesma família e a mudança para fora da abrangência da equipe durante o puerpério representavam obstáculos à cobertura da microárea pelo agente 20,25 .

A consulta puerperal tem baixa frequência na atenção primária à saúde, no Brasil, apesar de constituir uma das ações previstas no cuidado puerperal 1. Nesta pesquisa, as quatro mulheres que efetivaram revisão pós-parto procuraram a maternidade ou o ginecologista particular. A EqSF não oferece consulta pós-parto, nem marcação específica para puérperas, pois seriam atendidas no dia em que demandavam. Porém, diante dos obstáculos na porta de entrada que se constituem como barreira ao cuidado no puerpério, a observação a seguir ilustra como a enfermeira interpreta a mediação da agente.

"A ACS bate na porta da sala e insiste para a enfermeira atender uma mulher. $O$ atendimento é agendado para segunda-feira à tarde. Depois da ACS retirar-se, ela me diz que esta agente sempre fica 'chorando' para que atenda aos usuários da microárea dela" (Diário de Campo, 18/Out/2012). 
As mulheres queixam-se do difícil acesso à consulta médica e solicitam a obrigatoriedade da realização da consulta puerperal com esta profissional, afirmando competir às ACS agendar essa consulta, porém elas não procuram conhecer as necessidades e não facilitam a marcação. A visita domiciliar como facilitador do acesso aos serviços de saúde era comum entre usuários da ESF 23,26. A percepção das marcações de consultas ou entregas de encaminhamentos como inerente ao trabalho dos ACS é maior quando o foco do trabalho deles é a operacionalização destas atividades 26.

Segundo o definido na USF, a marcação de consulta deve ser efetuada pelos usuários, uma vez por mês, na recepção do serviço. As puérperas apontam falhas da recepção: desorganização do agendamento, perda de prontuários e dificuldade para obter informação. Apenas uma delas que demandou por dificuldade na amamentação aprova o atendimento na recepção, apesar de relatar atitude de rechaço da médica.

"Ele [recepcionista] tentou de várias formas pra eu falar com a médica, mas ela - não vou atender hoje não, eu estou atrasada, tem muita gente pra atender, mande ela voltar outro dia ou marcar pra poder voltar" (M1).

A recepção é um lugar de conflito porque recebe todos os usuários que chegam, com diferentes demandas, e precisa encaminhá-los dentro das alternativas do serviço 7,8 . Teixeira 9 argumentou que a tensão advinda das dificuldades em lidar com a alteridade não é exclusiva da recepção, mas que esse é o momento de iniciar a negociação das necessidades que podem vir a ser satisfeitas, denominando de acolhimento-diálogo o processo de negociação que deve ser promovido no itinerário do usuário pelo serviço.

Da perspectiva de Penchansky \& Thomas ${ }^{19}$, identificou-se a falta de sintonia entre arranjos organizacionais relacionados ao acesso ao cuidado puerperal e necessidades percebidas pelas mulheres. A insatisfação era generalizada, sobretudo, quanto à oferta de atividades, periodicidade da visita domiciliar, agendamento de consultas e falta de critério de priorização. Gadamer 12 reconheceu a importância do acesso a todos os recursos tecnológicos que possibilitem ampliar o auxílio à saúde, mas questionou o tecnicismo que obscurece o processo intersubjetivo de compreensão e crítica. A diversificação na percepção de necessidades torna essencial o diálogo entre os saberes técnicos e os pressupostos e expectativas das pessoas, para que sejam feitas as escolhas mais adequadas nas diversas situações.

\section{As demandas e necessidades de saúde}

$\mathrm{Na}$ esfera das práticas, o acolhimento deve ser pessoa-centrado, visando a identificar e negociar alternativas para atender as demandas e necessidades de saúde. Para ampliar as possibilidades de auxílio à puérpera, o encontro profissional/usuário precisa conter: (a) competência técnica para, no seu núcleo profissional específico, escolher as melhores respostas para o problema apresentado; (b) postura ética para o profissional mobilizar seu saber-fazer, considerando a singularidade da situação de aplicação do conhecimento; e (c) capacidade de construir vínculos com quem precisa do seu cuidado 14 .

Para as puérperas, o bom atendimento resulta do interesse demonstrado no exame físico, perguntas feitas e orientações dadas, resolutividade das condutas adotadas e relações interpessoais. Confirmando o demonstrado noutros contextos 8,11, a percepção do interesse relaciona-se ao tempo dedicado ao atendimento, sendo quase unânime a solicitação das mulheres que as profissionais dediquem mais tempo a elas.

"Eu achei o atendimento muito rápido, ela [enfermeira] deveria explicar mais, dar mais atenção, mas ela foi muito rápida” (M8).

Conforme concebem, todas as mulheres devem passar por exame físico, cuja extensão e minúcia dependem de quem presta o cuidado. Ao ACS cabe examinar mamas e pontos. Ao médico e enfermeiro compete efetivar exame físico completo, sendo mais detalhado no caso do médico.

"Eu acho que ela [médica] devia consultar a gente nua, conferir o peito da gente, olhar o corpo da gente" (M10).

A formulação de perguntas pelos membros da EqSF sobre a saúde da mulher é muito desejada porque elas querem esclarecer dúvidas relativas ao cuidado dos filhos, e não indagam sobre as próprias necessidades. Existe ainda autocensura: "às vezes quero falar e não sei falar, mas se a pessoa perguntasse ficaria mais fácil” (M2). Pensam que o saber técnico, especialmente o dos médicos, possibilita levantar questões que auxiliam no autocuidado, mas esperam que todos procurem saber como estão se sentindo e se precisam de algo. 
Para Gadamer 12, o paciente/usuário recorre ao médico/profissional de saúde por ele dispor de um saber diferente do seu saber prático, que cria uma expectativa de resolução do problema de saúde. Ao profissional compete gerar uma rede de conversações, na qual a investigação, elaboração e negociação de necessidades sejam engendradas pelo conjunto dos saberes presentes. É a pergunta que possibilita outras perspectivas, tendo primazia numa conversação que queira compreender alguma coisa. O diálogo deve ser entendido como uma dialética de pergunta e resposta, cujo sentido não está dado a priori, sendo tecido no transcurso da conversação.

Os relatos das mulheres e a observação constatam atendimento focado na pauta técnica referida à saúde da criança, assim elas não se sentem devidamente contempladas em suas necessidades. Praticamente não foram efetuados exame físico e anamnese da puérpera. Nas visitas domiciliares das ACS, as atividades voltadas à mulher centraram-se nas orientações sobre cuidados com a mama, resguardo $\mathrm{e}$ pontos, também no questionamento do sangramento vaginal. Porém, algumas mulheres demonstram insatisfação com as orientações pelo provimento tardio e/ou insuficiência do conteúdo. Há referência pontual ao interesse pela situação da puérpera.

"Nem perguntaram como é que eu estou, pergunta pela menina, mas comigo não me perguntaram nem se eu sinto dor de cabeça. Até o sulfato ferroso eu pedi, porque a receita veio da maternidade" (M6).

"Quando chegamos à residência, a ACS foi logo perguntando e orientando os cuidados do bebê. Depois instruiu a puérpera a não pegar peso e interrogou sobre sangramento vaginal. A mulher expressou o desejo de realizar laqueadura tubária, sendo orientada como proceder. Não investigou outras necessidades de saúde femininas" (Diário de Campo, 11/Dez/2012).

$\mathrm{Na}$ consulta de puericultura, a anticoncepção foi tratada com quase todas as mulheres, com metade delas abordando o tema. Em geral, a enfermeira prescreveu anticoncepcional e orientou como utilizá-lo (início, horário, continuidade, permanecer amamentando). Raramente investigou algum aspecto da pauta técnica relativa à puérpera. Apesar de mostrar-se afável e comunicativa ao atender à criança, não facilitou a troca de informação e o esclarecimento de dúvidas acerca da saúde feminina. Essa atitude favorece a percepção das mulheres de que esse espaço é inapropriado para atender as suas necessidades de saúde.

"Durante os meses em que venho observando as consultas de puericultura, foi a primeira vez que a enfermeira interrogou a puérpera sobre o uso do sulfato ferroso" (Diário de Campo, 18/Jun/2013).

As ações voltadas à puérpera visam a: escutar sentimentos e queixas; esclarecer dúvidas; efetivar avaliação clínico-ginecológica; acompanhar as mudanças orgânicas da mulher; investigar as condições psicoemocionais; desenvolver ações de planejamento familiar e prevenção (câncer de mama, câncer de colo uterino e doenças sexualmente transmissíveis); orientar sobre alimentação, atividades físicas, retorno à atividade sexual; e apoiar a amamentação 1. A escassa execução da anamnese e exame físico, instrumentos fundamentais para identificar problemas, definir diagnósticos, desenvolver ações e acompanhar a evolução do paciente demonstrou a baixa qualidade técnica do cuidado puerperal. Uma metassíntese identificou que as puérperas expressaram insatisfação com o atendimento de suas necessidades, principalmente pela focalização no bebê, desatenção às primíparas e abordagem clínica falha 11 .

As puérperas diferenciam o potencial de resolutividade do cuidado à saúde da mulher prestado pela enfermeira, atribuindo maior capacidade de auxílio às ações a serem desenvolvidas na visita domiciliar no puerpério imediato. Há percepção unânime de que o conhecimento técnico dessa profissional é insuficiente para realizar a consulta puerperal. Então, sugerem que a consulta seja realizada pela médica ou pela enfermeira juntamente com a médica.

"Por ela ser enfermeira, tem que ter uma médica perto dela, porque se tiver alguma coisa errada a médica já orienta, já passa um remédio, ela não pode passar todos os remédios" (M5).

Os depoimentos das mulheres dão ênfase à especificidade e superioridade do saber médico. Ao prestar atendimento rápido à anticoncepção, a enfermeira certamente fortaleceu a visão hierarquizada do trabalho. Os saberes e responsabilidades comuns conferem flexibilidade à divisão do trabalho, traduzindo a coexistência de ações privativas das respectivas áreas profissionais e ações que são executadas indistintamente por profissionais de diferentes campos de atuação. As diferenças técnicas indicam a possibilidade de contribuição da divisão do trabalho para melhor prestação de serviços, cabendo à instituição assegurar a cooperação intraequipes 27 . 
Várias mulheres falam do distanciamento na relação com a médica e sentem-se pouco à vontade: "eu não tenho tanta vergonha com a enfermeira, eu tenho mais vergonha com a médica" (M6). A única mulher que se consultou com essa profissional para a prescrição de anticoncepcional conta que "ela não falou quase nada, o atendimento dela eu achei muito rápido" (M8).

A relação profissional de saúde/usuário é fundamental, pois confiança, vínculo e corresponsabilidade dependem da qualidade das interações 3,4,6. Neste estudo, há mulheres que dizem manter relação amigável com a ACS, e outras expressam antipatia. A interação com a enfermeira também suscita percepções distintas: para a maioria das puérperas ela é simpática, comunicativa, mas tem quem afirme que ela é "fechada", de poucas palavras. Diferentes pesquisas encontraram opiniões contraditórias sobre a interação profissional/usuário 11,23, sugerindo que a situação do encontro condiciona a comunicação entre eles.

As mulheres entendem existir um bom relacionamento quando o profissional é atencioso, paciente e comunicativo. Elas sentem necessidade de exprimir pensamentos e sentimentos relacionados à situação vivenciada. Existe grande carência de apoio emocional. A falta de diálogo sobre as demandas da mulher é motivo de insatisfação, em consonância com outros estudos 11,28.

"Teve um momento que eu me senti muito estressada pela questão de querer conversar, tirar algumas dúvidas e não tinha ninguém, sabendo que eu poderia ter tido a assistência do posto onde eu fiz o meu pré-natal” (M4).

"O importante não é só a pessoa cuidar fisicamente, e sim saber conversar, porque é o momento que a gente mais precisa de força, de segurança, de palavras de conforto” (M1).

Nesta pesquisa predominou uma comunicação profissional/mulher de caráter técnico, traduzindo a primazia de uma prática comunicativa que secundariza a participação dos usuários nas decisões sobre a sua saúde 3,29. Gadamer 12 reiterou a essencialidade da integração do saber-fazer instrumental com o diálogo, pois como o profissional de saúde depende da colaboração do paciente, torna-se impróprio separar a pessoa da sua doença/questão de saúde, descontextualizando o ocorrido. A cristalização desse modo de agir leva à desvalorização do diálogo que pode conduzir ao entendimento propiciador de uma assistência mais compreensiva e resolutiva.

Comumente as mulheres consideram inteligível a linguagem utilizada pela enfermeira e ACS. Porém, a falta de adesão generalizada ao anticoncepcional prescrito pela profissional, sem negociação de interesses conflitantes, exemplificou que a compreensão alcançada não era mediada por valores e significados vigentes no grupo 3,4. A convicção arraigada da ineficácia do medicamento adequado ao pós-parto e do risco de efeitos indesejáveis na saúde do bebê justifica a persistência no uso da camisinha.

Poucas puérperas expressam necessidades de saúde que provocam inquietações e angústias, conforme os relatos das suas vivências. Calam-se as dúvidas sobre peso corporal, prevenção, temor da relação sexual no pós-parto cirúrgico, insegurança quanto ao contraceptivo indicado, incômodos físicos (dor abdominal, ardor e irritação no ato sexual) e dificuldades emocionais (desmotivação e diminuição da libido).

A relação com parceiros íntimos é uma questão importante, pois uma grande proporção de mulheres apresenta incômodos físicos e dificuldades emocionais no retorno à atividade sexual; embora estes aspectos pareçam ser pouco considerados pelos profissionais de saúde. Em investigação com primíparas realizada em Melbourne (Austrália), verificou-se que, nos primeiros três meses pós-parto, os médicos e enfermeiros da atenção primária à saúde perguntaram sobre problemas de saúde sexual a, respectivamente, $13 \%$ e $23 \%$ das mulheres 30 .

As puérperas manifestam o sentimento de vulnerabilidade emocional. Para algumas, conversar com o médico é fundamental para identificar necessidades relacionadas às condições psicoemocionais. A observação indica que a equipe não oferece o cuidado preconizado 1 . Nesse período, 50\% a 70\% das puérperas apresentam um estado depressivo brando (blues) que aparece, em geral, no terceiro dia pós-parto e tem duração aproximada de duas semanas. A depressão pós-parto é um fenômeno menos comum e necessita de acompanhamento especializado 1.

“Tem mãe que tem aqueles problemas que precisam ir pra psicólogo, essas coisas. Conversar mesmo, não como médico, como amigas, pra mãe dizer o que precisa e a médica orientar ela certo, no que ela precisa ir" (M5).

Brehmer \& Verdi 6 revelaram a emergência de conflitos éticos no cotidiano das equipes de atenção primária à saúde, decorrentes do distanciamento entre discurso e prática do acolhimento. Algo semelhante ocorreu neste estudo. A EqSF dispensava atendimento técnico e relacional precários, apesar de 
serem frequentes os comentários sobre a importância da conversa para conhecer a singularidade das vivências no puerpério.

Segundo Gadamer, na boa prática em saúde, o profissional está tensionado pela necessária prudência na relação entre correção do atuar (saber técnico) e respeito aos modos singulares de interpretar e agir frente às necessidades e ações de saúde (saber prático). $\mathrm{O}$ encontro profissional/usuário não deveria resumir-se à aplicação acrítica do conhecimento técnico-científico 12 . O não reconhecimento da mulher como interlocutora aumenta a insatisfação de necessidades sentidas e limita a busca daquelas mais silenciosas. Restringe ainda o potencial resolutivo das ações. Um saber que não saiba aplicarse à situação concreta pode até obscurecer as necessidades presentes numa determinada situação 13 .

Por outro lado, o ACS pode não ser reconhecido como interlocutor pelas mulheres. A obrigatoriedade de exercer as suas atividades na mesma área onde reside, faz com que a confiança assuma um caráter indispensável nas relações entre ACS e usuário. Seoane \& Fortes 31 constataram a preferência dos usuários para recorrer ao médico ou enfermeiro quando o assunto é confidencial, temendo que o ACS revele informações sigilosas. Neste estudo, evidenciou-se temor quanto à discrição da ACS. A presença da agente levou a puérpera a não falar o que necessitava.

"Era uma coisa pessoal, eu só queria perguntar a ela [enfermeira] mesmo porque tem coisa que a gente só fala com a médica, com a enfermeira" (M2).

"No meu pensamento eu acho que ela não vai contar, mas o meu sentido diz que ela vai contar. Eu não converso essas coisas de marido e mulher porque ela mora aqui perto" (M6).

No entanto, embora o desempenho da EqSF no cuidado puerperal tenha motivado grande insatisfação entre as mulheres, duas delas se mostraram satisfeitas com a disponibilidade e o tratamento recebido da ACS desde o pré-natal. Nessas vivências são esboçados dois elementos essenciais ao vínculo: longitudinalidade e confiança. O vínculo é influenciado pela percepção do acolhimento, sendo a verdadeira fonte de corresponsabilidade 3,8 .

Apesar de insatisfeitas com a desconsideração por necessidades de saúde relativas às vivências do puerpério, as mulheres pareciam sentir dificuldade de transformá-las em demanda, denotando certa passividade no processo de buscar o cuidado à saúde. Postura que pode ter sido influenciada por expectativas sociais referidas ao exercício da maternidade, que enfatizam a centralidade do cuidado ao filho e alimentam a postergação do cuidado de si. Convém atentar-se que o menoscabo pelas necessidades femininas não pode ser exercido sem a colaboração da mulher. Ademais, na literatura é reconhecido o viés de gênero nas práticas de saúde, levando a dar atenção à saúde da mãe e não à da mulher 32. O poder simbólico relativo às questões de gênero é elemento importante da difícil tarefa colocada aos profissionais e pacientes de estabelecer um diálogo que inaugure o tratamento e acompanhe a cura 12 .

\section{Considerações finais}

As limitações técnicas, relacionais e organizacionais das práticas de saúde desenvolvidas pela EqSF, originando a pouca visibilidade das necessidades específicas da mulher no puerpério, revelaram a incipiência do processo de acolhimento. Portanto, manifestaram a distância entre a pretensão institucional de ampliar acesso e qualificar atendimento, articulando o conhecimento técnico-científico à atitude ética e solidária, e o cotidiano da organização e processo de trabalho. Essa distância evidencia desvalorização do pós-parto nas políticas públicas de saúde, em comparação a outras fases do ciclo gravídico-puerperal.

A distância entre previsto e realizado não decorre apenas das incertezas na implantação de ações, devido às condições objetivas e subjetivas das situações de trabalho. Aspecto fundamental é a expressão de compromisso por parte das esferas de gestão, o planejamento, coordenação e gerenciamento das ações, assegurando, entre outros, a capacitação e o apoio logístico e operacional requerido para viabilizar o modelo assistencial da ESF, visando a responder às necessidades de saúde da puérpera.

A comunicação profissional/mulher, voltada apenas à instrumentalização da técnica, foi um elemento importante da inadequação do acesso e das práticas de saúde no puerpério. De um lado, a ausência de um projeto em comum agravava as incertezas acerca dos critérios de priorização e do papel a ser desempenhado por cada trabalhador no pós-parto. De outro, a unilateralidade da prática 
comunicativa não possibilitou a negociação do acesso ao atendimento no puerpério. O não reconhecimento da mulher como interlocutora alimentou a pouca visibilidade de suas necessidades para a EqSF e reforçou o silêncio sobre demandas.

As puérperas revelaram desconforto pela atenção focalizada no bebê, com reconhecimento unânime de que a visita domiciliar e a consulta de puericultura não constituíram um espaço para acolher suas angústias, receios, desejos e necessidades. Nesse contexto, a importância conferida à iniciativa do profissional em questionar as necessidades da mulher permite conjeturar sobre a aspiração de, desse modo, legitimar o próprio lugar para além da condição de mãe.

Portanto, o processo de acolhimento implica transformações profundas nas concepções e práticas dos gestores, dos profissionais de saúde e das mulheres. Nesse sentido, os membros das EqSF necessitam ser capacitados para o cuidado puerperal, incluindo conhecimento técnico-científico e habilidades comunicacionais. Também precisam elaborar um projeto comum de atuação, realizar reuniões periódicas para reorganizar os processos de trabalho, assegurar a sustentabilidade das mudanças no trabalho, mediante supervisão sistemática para fornecer suporte técnico, psicossocial, material e informacional às equipes, bem como realizar avaliação continuada.

\section{Colaboradores}

Todas as autoras participaram da concepção, análise, interpretação dos dados e redação do artigo. M. S. M. Corrêa realizou a coleta dos dados.

\section{Referências}

1. Área Técnica de Saúde da Mulher, Departamento de Ações Programáticas Estratégicas, Secretaria de Atenção à Saúde, Ministério da Saúde. Pré-natal e puerpério: atenção qualificada e humanizada - manual técnico. 3a Ed. Brasília: Ministério da Saúde; 2006.

2. Departamento de Atenção Básica, Secretaria de Atenção à Saúde, Ministério da Saúde. Política Nacional de Atenção Básica. Brasília: Ministério da Saúde; 2012.

3. Ayres JRCM. Organização das ações de atenção à saúde: modelos e práticas. Saúde Soc 2009; 18 Suppl 2:S11-23.

4. Núcleo Técnico da Política Nacional de Humanização, Secretaria de Atenção à Saúde, Ministério da Saúde. Acolhimento nas práticas de produção de saúde. Brasília: Ministério da Saúde; 2010.

5. Garuzi M, Achitti MCO, Sato CA, Rocha SA, Spagnuolo RS. Acolhimento na Estratégia Saúde da Família: revisão integrativa. Rev Panam Salud Pública 2014; 35:144-9.

6. Brehmer LCF, Verdi M. Acolhimento na Atenção Básica: reflexões éticas sobre a atenção à saúde dos usuários. Ciênc Saúde Coletiva 2010; 15 Suppl 3:3569-78. 
7. Takemoto MLS, Silva EM. Acolhimento e transformações no processo de trabalho de enfermagem em unidades básicas de saúde de Campinas, São Paulo, Brasil. Cad Saúde Pública 2007; 23:331-40.

8. Lopes GVDO, Menezes IMO, Miranda AC, Araujo KL, Guimarães ELP. Acolhimento: quando o usuário bate à porta. Rev Bras Enferm 2014; 67:104-10.

9. Teixeira RR. O acolhimento num serviço de saúde entendido como uma rede de conversações. In: Pinheiro R, Mattos RA, organizadores. Construção da integralidade: cotidiano, saberes e práticas em saúde. Rio de Janeiro: Abrasco; 2003. p. 89-111.

10. Schraiber LB. Quando o 'êxito técnico' se recobre de 'sucesso prático': o sujeito e os valores no agir profissional em saúde. Ciênc Saúde Coletiva $2011 ; 16: 3041-42$.

11. Correa MS, Feliciano KV, Pedrosa EN, Souza AI. Women's perception concerning health care in the post-partum period: a meta-synthesis. Open J Obstet Gynecol 2014; 4:416-26. http:// dx.doi.org/10.4236/ojog.2014.47062.

12. Gadamer HG. O caráter oculto da saúde. Petrópolis: Editora Vozes; 2006.

13. Gadamer HG. Verdade e método. Petrópolis: Editora Vozes; 1997.

14. Cecílio LCO. Apontamentos teórico-conceituais sobre processos avaliativos considerando as múltiplas dimensões da gestão do cuidado em saúde. Interface Comun Saúde Educ 2011; 15:589-99.

15. Flick U. Introdução à pesquisa qualitativa. 3a Ed. Porto Alegre: Editora Artmed; 2009.

16. Minayo MCS. O desafio do conhecimento: pesquisa qualitativa em saúde. 13a Ed. Rio de Janeiro: Abrasco; 2013

17. Fontanella BJB, Ricas J, Turato ER. Amostragem por saturação em pesquisas qualitativas em saúde: contribuições teóricas. Cad Saúde Pública $2008 ; 24: 17-27$.

18. Medeiros CRG, Junqueira AGW, Schwingel G, Carreno I, Jungles LAP, Saldanha OMFL. A rotatividade de enfermeiros e médicos: um impasse na implementação da Estratégia de Saúde da Família. Ciênc Saúde Coletiva 2010; 15 Suppl 1:1521-31.

19. Penchansky DBA, Thomas JW. The concept of access - definition and relationship to consumer satisfaction. Med Care 1981; 19:127-40.

20. Kebian LVA, Acioli S. A visita domiciliar de enfermeiros e agentes comunitários de saúde da Estratégia Saúde da Família. Rev Eletrônica Enferm 2014; 16:161-9. http://dx.doi. org/10.5216/ree.v16i1.20260.
21. Cunha MS, Sá MC. Home visits within the Family Health Strategy (Estratégia de Saúde da Família - ESF): the challenges of moving into the territory. Interface Comun Saúde Educ 2013; 17:61-73.

22. Say L, Chou D, Gemmil A, Tumcap O, Moller A, Daniels J, et al. Global causes of maternal dealth: WHO sistematic analyses. Lancet Glob Health 2014; 2:e322-33. http://www.thel ancet.com/pdfs/journals/langlo/PIIS2214 109X(14)70227-X.pdf.

23. Cruz MM, Bourget MMM. A visita domiciliária na Estratégia de Saúde da Família: conhecendo as percepções das famílias. Saúde Soc 2010; 19:605-13.

24. Oliveira DC, Mandú ENT, Corrêa ACP, Tomiyoshi JT, Teixeira RC. Organizational structure of postpartum care in Family Health Strategy. Esc Anna Nery Rev Enferm 2013; 17:446-54.

25. Bernardi MC, Carraro TE, Sebold LF. Visita domiciliária puerperal como estratégia de cuidado de enfermagem na atenção básica: revisão integrativa. Rev RENE 2011; 12(n. esp.): 1074-80.

26. Sakata KN, Mishima SM. Cooperative interventions and the interaction of Community Health Agents within the Family Health team. Rev Esc Enferm USP 2012; 46:662-9.

27. Ladhani Z, Stevens FJ, Scherpbier AJ. Does community health care require different competencies from physicians and nurses? BMC Med Educ 2014; 14:1.

28. Mclellan J, Laidlaw A. Perceptions of postnatal care: factors associated with primiparous mothers perceptions of postnatal communication and care. BMC Pregnancy Childbirth 2013; 13:1-9.

29. Campos GWS. A mediação entre conhecimento e práticas sociais: a racionalidade da tecnologia leve, da práxis e da arte. Ciênc Saúde Coletiva 2011; 16:3033-40.

30. Woolhouse H, McDonald E, Brown SJ. Changes to sexual and intimate relationships in the postnatal period: women's experiences with health professionals. Aust J Prim Health 2014; 20: 298-304.

31. Seoane AF, Fortes PAC. A percepção do usuário do Programa Saúde da Família sobre a privacidade e a confidencialidade de suas informações. Saúde Soc 2009; 18:42-9.

32. Gutierrez DMD, Minayo MCS. Papel da mulher de camadas populares de Manaus na produção de cuidados da saúde. Saúde Soc 2009; 18 : 707-20. 


\section{Abstract}

This study focused on perceptions and practices in postpartum follow-up of women's health. The article is part of a larger qualitative study based on Gadamer, from October 2012 to September 2013 in Recife, Pernambuco State, Brazil, with participant observation and semi-structured interviews. Participation included the family health team (a physician, nurse, and five health agents) and ten women (18 years or older, recruited in the last trimester of pregnancy, and receiving prenatal care with the family health team). The empirical categories were access to care and health demands and needs. The results highlight dissatisfaction with home visits: late, without priority, absent physician or nurse, irregular and discontinuous; lack of postpartum appointment; and difficult access to the physician. The women expressed displeasure with the limited appreciation of women's health needs: attention focused on the infant, scarcity of physical examination and patient history, insufficient orientation, and limited communication. The incipient characteristics of postpartum follow-up in this study show the need to transform the health team's practices to focus more attention on the woman, thereby improving postpartum care.

User Embracement; Postpartum Period; Primary Health Care; Delivery of Health Care; Women's Health

\section{Resumen}

Este artículo tuvo como objetivo comprender las percepciones y prácticas relativas a la atención durante el cuidado puerperal de la mujer. Forma parte de una investigación cualitativa más amplia fundamentada en Gadamer, efectuada de octubre de 2012 a septiembre de 2013, en Recife, Pernambuco, Brasil, con observación participante y entrevistas semiestructuradas. Participaron el equipo de salud de la familia (médica, enfermera y cinco agentes de salud), además de diez mujeres (18 años o más, en el último trimestre de gestación, bajo cuidado prenatal del equipo médico). Las categorías empíricas fueron: acceso al cuidado, demandas y necesidades de salud. Los resultados destacan la insatisfacción con la visita domiciliaria: tardía sin priorización, médica/enfermera ausente, asistemática y descontinuada; falta de consulta puerperal y acceso difícil al médico. Existe desagrado con la desvalorización de las necesidades de salud femeninas: atención enfocada en el bebé, escasez de examen físico y anamnesis, orientaciones insuficientes y comunicación limitada. La insipiencia de la acogida expone la necesidad de transformar las prácticas del equipo para verificar la visibilidad de la mujer, cualificando el cuidado puerperal.

Acogimiento; Periodo Posparto; Atención Primaria de Salud; Prestación de Atención de Salud;

Salud de la Mujer

Recebido em 21/Ago/2015

Versão final reapresentada em 20/Abr/2016

Aprovado em 30/Mai/2016 